\title{
Nefroloji Düşük Klirens Polikliniğinde Arteriovenöz Fistülü Hazır Hemodiyalize Başlamayan Hastalarda Arteriovenöz Fistül Eğitimlerinin Değerlendirilmesi: Pilot Çalışma
}

\author{
Evaluation of Arteriovenous Fistula Training of Follow-Up \\ Patients in Nephrology Low Clirens Outpatient Clinic who Do \\ Not Undergo Hemodialysis with Proper Working \\ Arteriovenous Fistula: A Pilot Study
}

\author{
Emine ASAR ${ }^{1}$, Feyza BORA ${ }^{2}$
}

${ }^{1}$ Hemşire-Akdeniz Üniversitesi Hastanesi Nefroloji Düşük Klirens Polikliniği, Antalya, Türkiye

${ }^{2} \ddot{O} \breve{r}$. Gör. Uzm. Dr.- Akdeniz Üniversitesi Tıp Fakültesi Dahili Tıp Bilimleri Bölümü İ̧ Hastalıkları BD,

Antalya, Türkiye

*Bu çalışma 16-20 Ekim 2019 tarihleri arasında Antalya'da düzenlenen 29. Ulusal Böbrek Hastalıkları, Diyaliz ve Transplantasyon Hemşireliği Kongresi’nde sözlü bildiri olarak sunulmuştur.

Geliş Tarihi / Received :

12 Eylül/Sept 2020

Kabul Tarihi / Accepted:

29 Ocak/Jan 2021

İletişim yazarı /

Correspondence author

Emine ASAR

E-posta: emineasar@akdeniz.edu.tr

\section{ORCID}

Emine ASAR

0000-0003-2853-0778

Feyza BORA

0000-0003-2379-2090

\section{Özet}

Amaç: Kronik böbrek hastalığı, önemli bir halk sağlığı sorunudur. Hastaların kronik böbrek hastalığı progresyonları ve komplikasyonlarından korunması açısından düşük klirens poliklinikleri önemlidir. Renal replasman tedavilerinden hemodiyalize girmeye karar veren hastaların arteriyovenöz fistüllerinin hazır olarak diyalize geçmeleri hastaları kateter komplikasyonlarından korur. $\mathrm{Bu}$ çalışma; düşük klirens polikliniğinde arteriyovenöz fistülü hazır, hemodiyalize girmeyen hastalara verilen arteriyovenöz fistül bakım eğitimlerini değerlendirmek, eğitim eksiklerini tespit edip; takip ve eğitimlerinin yeniden düzenlenmesi amacıyla planlandi.

Gereç-Yöntem: Bu çalışmaya Antalya'da bir üniversite hastanesinin nefroloji düşük klirens polikliniğinde kronik böbrek hastalığı nedeniyle takipte olan ve renal replasman tedavi kararı olarak hemodiyalizi seçmiş, hemodiyalize girmeyen ve arteriyovenöz fistülü hazır bekleyen; 1-30 Haziran 2019 tarihleri arasında kontrole gelen 23 hastadan çalışmaya katılmaya gönüllü olan toplam 20 hasta dahil edildi.

Bulgular: Çalışmaya dahil edilen hastaların \%80'i erkek cinsiyette idi. Evre 5 takip süreleri ortancası 16 ay (min:2-max:156), arteriyovenöz fistül takip süreleri ortancası 11 ay (min:2 max:156) ve arteriyovenöz 
fistül açtırma kararı verildiğinde glomerüler filtrasyon hızı ortancası 10,90 ml/dk (min:7-max:15,90) olduğu tespit edildi. Arteriyovenöz fistül, iki hastada aktif kullandığı kolda olup; bu hastalarda, ikinci kez arteriyovenöz fistül açılmıştı. Hastaların fistüllerinin kontrolü ve korunması konularında yapması gereken davranışları yeterli bulundu. Isı değişimlerinin ve hipotansiyon durumunun fistülü etkilemesi ile ilgili bilgi düzeyleri ise yetersiz bulundu.

Sonuç: Henüz hemodiyalize girmeyen hastalar, açılan arteriyovenöz fistülün öneminin farkında olmayabilirler. $\mathrm{Bu}$ hasta grubunda; arteriyovenöz fistül bakımı ile korunması hakkında eğitim verilip, basılı eğitim broşürleri ile bu eğitimler pekiştirilmelidir. Arteriyovenöz fistülü açılmış hazır şekilde takip edilen hastaların her ay rutin muayeneleri yapılmalı, muayene sırasında arteriyovenöz fistülü kontrol edilmeli ve arteriyovenöz fistülün korunması için eğitim kontrol formlarının oluşturulması önerilir.

Anahtar kelimeler: Düşük Klirens Polikliniği, Arteriyovenöz Fistül, Eğitim Hemşiresi

\begin{abstract}
Objective: Chronic kidney disease is an important public health problem. Low clearance polyclinics are important for protecting patients from chronic kidney disease progression and complications. The readiness of arteriovenous fistulas of patients who decide to undergo hemodialysis for renal replacement therapies protects patients from catheter complications. This study was planned to evaluate the arteriovenous fistula care training of patients with proper working arteriovenous fistula and who did not undergo hemodialysis in the low clearance outpatient clinic and to rearrange their follow-up and training.
\end{abstract}

Method: In this study, a total of 23 of 20 patients who accepted to enter the study and who came for control visit between 1 - 30 June 2019 were included. They were followed up in the nephrology low clearance polyclinic of a university hospital in Antalya due to chronic kidney disease and chose hemodialysis as the decision of renal replacement treatment, did not undergo hemodialysis and had a proper working arteriovenous fistula.

Results: $80 \%$ of the patients included in the study were male. The median of the stage 5 chronic kidney disease follow-up time was 16 months (min: 2-max: 156), the median of the follow-up time with arteriovenous fistula was 11 months (min: 2 max: 156), and the median of the glomerular filtration rate was $10.90 \mathrm{ml} / \mathrm{min}$ (min: 7 max: 15.90). Four (20\%) of the arteriovenous fistulas were formed for the second-time. The arteriovenous fistula was in the active arm in two patients, these patients were those who had a second-time arteriovenous fistula. The patients' actions to control and protect their fistulas were found to be sufficient but knowledge about the effects of temperature changes and low blood pressure on the fistula was inadequate.

Conclusion: The patients who have not yet undergone hemodialysis may not be aware of the importance of properly working arteriovenous fistula. In these patients group; these pieces of training should be reinforced with printed educational brochures for providing training on the care and protection of arteriovenous fistula. Patients whose arteriovenous fistulas have been formulated before and are followed up ready should be routinely examined every month, their arteriovenous fistulas should be checked during the examination and training control forms should be created for arteriovenous fistula protection.

Key words: Low Clearance Outpatient Clinic, Arteriovenous Fistula, Education Nurse

\section{GİRIŞ}

Kronik böbrek hastalığı (KBH), çeşitli hastalıklara bağlı olarak gelişen kronik, progresif ve geri dönüşümsüz nefron kaybı ile karakterize olan bir nefrolojik sendromdur. KBH'nın tanımı ve evrelerine ilişkin kılavuz 2002 yılında National
Kidney Foundation (NKFKDOQI) tarafindan yayınlandıktan sonra düşük klirens eğitimleri tüm dünyada gündeme gelmeye başlamıştır (1). Düşük klirens poliklinikleri, Evre 4-5 kronik böbrek hastalarını yakından izleyerek; KBH'nın ilerlemesini engellemek ve uygun zamanda hastanın en uygun renal replasman tedavi (RRT) 
kararını vermesini kapsayan, geniş zamana yayılan bir eğitim programıdır. Glomerül filtrasyon hız1 (eGFH) $30 \mathrm{ml} / \mathrm{dk} / 1,73 \mathrm{~m}^{2}$ altına düştüğü zaman hastalar daha yakından; multidisipliner bir ekip tarafından izlenmelidir. Nefrolog, eğitim hemşiresi, psikolog, sosyal hizmet uzmanı ve diyetisyen bu ekibin içindedir (2). Son dönem böbrek hastalığ1 ile takipte olan, RRT olarak hemodiyalizi (HD) seçen hastalara; HD başlangıcında, kalıcı bir damar erişimine, tercihen bir arteriyovenöz fistüle (AVF) sahip olmaları önerilmektedir (3-5). Tahmini diyalize başlangıç tarihinden 4-6 ay öncesinden AVF oluşturulmalıdır (6-10). AVF ile diyalize başlayan hastalarda, diğer girişim yollarına sahip hastalara kıyasla; mortalite, enfeksiyon riski, kateter komplikasyonları, hastaneye yatış ve kalış oranları, stenoz ve tromboz görülme oranları önemli ölçüde düşüktür. Toplam maliyet konusunda da daha düşük maliyete sahiptir (11-20). Tüm bu verilerin 1şığında düşük klirens polikliniğinde kişiye özel eğitimlerle RRT tercihini HD olarak belirleyen hastalara uygun zamanda AVF açılması için yönlendirme yapılmaktadır. AVF açılmasının üzerinden belli bir zaman geçmesi sonrası HD'ye geçecek grup olmaları nedeniyle hastalar AVF bakımı ve korumasına HD tedavisine devam eden hastalar kadar özen göstermeyebilmektedirler. $\mathrm{Bu}$ pilot çalışma; düşük klirens polikliniğinde AVF'si hazır, henüz HD'ye girmeyen hastalara verilen AVF eğitimlerini değerlendirmek, eğitim eksiklerini tespit edip takiplerin ve eğitim içeriklerinin yeniden düzenlenmesi amacıyla yapıldı.

\section{GEREÇ VE YÖNTEM}

\section{Araştırmanın Tipi}

Tanımlayıcı ve kesitsel tiptedir.

\section{Araştırmanın Yeri ve Zamanı}

Araştırma, 1-30 Haziran 2019 tarihleri arasında Antalya'da bir üniversite hastanesinin nefroloji düşük klirens polikliniğinde yürütüldü.

\section{Araştırmanın Evren ve Örneklemi}

Araştırmanın evrenini, çalışmanın yürütüldüğü nefroloji düşük klirens polikliniğinde takip ve tedavisi devam eden, RRT kararı olarak HD seçmiş henüz HD tedavisine başlanmayan AVF'si hazır bekleyen 23 hasta oluşturdu. Bu evren içinden 18 yaş ve üstü, anket ve bilgi formundaki soruları anlamada engeli olmayan ve çalışmaya katılmaya gönüllü olan 20 hasta araştırmanın örneklemini oluşturdu.

\section{Veri Toplama Araçları}

Araştırmacılar tarafından ilgili literatür incelenerek (28-30) geliştirilen veri toplama formunun ilk bölümü hastaların demografik özelliklerinin ve AVF'lerinin durumunun belirlenmesi, ikinci bölüm hastaların fistülünün hemşire ve nefrolog tarafindan muayene edilmesi ve üçüncü bölüm hastanın fistül bakımı ve korunması konusunda bilgi düzeylerinin değerlendirilmesi amacına yönelik olarak hazırlanmış anket sorularından oluşmaktadır.

Hasta Tanıtım Formu: Form, hastaların yaşı, cinsiyeti, eğitim durumu, KBH etiyolojileri, aktif çalışma durumu, daha önceden fistül açıldıysa toplam açılan fistül sayısı, aktif çalışan AVF'nin izlem süresi, AVF lokalizasyonu, fistül açıldığinda eGFH, evre $5 \mathrm{KBH}(\mathrm{eGFH} \leq 15 \mathrm{ml} / \mathrm{dk}$ ve HD başlanmayan) takip süresini içermektedir.

Fistül Bakımı ve Korunması Konusunda Bilgi Düzeyi ve Davranış Anketi: Araştırmaya katılan hastaların fistül bakımı ve korunması konusunda bilgi ve davranışlarını belirlemek amacıyla hazırlanan 13 soru içeren bilgi formu eğitim hemşiresi tarafindan hastalara maddeler tek tek okunarak dolduruldu. Hastanın AVF'nin çalışmasını etkileyen durumların farkında olup olmadığının belirlenmesi için evet/hayır yanıtlı sorular; AVF'li kolun korunması ve bakımı konusundaki bilgi düzeylerini tespit etmek için evet/hayır/bazen yanıtlı sorular hastaya yöneltildi.

\section{Veri Toplama Yöntemi}

Araştırmanın verileri yüz yüze görüşme yöntemiyle topland. Hastalar takip ve tedavileri için kontrole geldiklerinde araştırma hakkında bilgi verildi. Çalı̧smaya katılmaya gönüllü olan hastalara Bilgilendirilmiş Gönüllü Olur Formu doldurulduktan sonra AVF'leri hemşire ve nefrolog tarafindan muayene edildi. Hasta tanitım formu ile fistül bakımı ve korunması konusunda bilgi ve davranış anket formlarındaki sorular 
eğitim hemşiresi tarafindan hastalara tek tek okunarak yanitları formlara kaydedildi. Hastanın AVF kontrolü ve formların doldurulması yaklaşı olarak 20-25 dakika sürdü. Hastaların laboratuvar bilgilerinden ve dosyalarından da yararlanıldı.

\section{Verilerin Değerlendirilmesi}

Çalışmada toplanan verilerin sayı, yüzde, ortanca, minimum ve maksimum değerleri alındı. Tanımlayıc istatistikler yapıld1. Veriler SPSS 23 paket programı kullanılarak değerlendirildi.

\section{Araştırmanın Etik Yönü}

Çalışmaya başlamadan önce araştırmanın yapılacağı hastane başhekimliğinden yazılı kurum izni alınd1 (11.4.2019/7730). Anket formları uygulanmadan önce katılımcılara araştırmanın amacı ve içeriği hakkında açıklama yapıldı, katılımcıların bilgilendirilmiş gönüllü onamları yazılı ve sözlü olarak alınd.

\section{Araştırmanın Sınırlılıkları}

Çalışmaya dahil edilen hasta sayısının kısıtlı olması ve hastaların fistül bakımıyla ilgili davranışlarının gözlenerek değil hastaların beyanına göre değerlendirilmesi çalışmanın sınırlılıklarını oluşturmaktadır.

\section{BULGULAR}

Çalışmaya dahil edilen 20 hastanın 16'sı (\%80) erkek, yaş ortancası 60 yaş (min:20-max:78) ve $\% 55$ 'nin ilkokul mezunu olduğu tespit edildi. Etiyolojiler arasında en çok görülen \%45 ile Diabetes Mellitus (DM) tanısı idi. Geri kalan kısmın içinde \% 25 bilinmeyen, her biri $\% 5$ olmak üzere polikistik böbrek hastalığı, fokal segmental glomerüloskleroz, steroid olmayan antiinflamatuar ilaçlar, nefrolityazis, enfektif endokardit sonras1 mitral kapak replasmanı ve kemoterapiye bağlı ikincil $\mathrm{KBH}$ vardı. Aktif çalışma durumlarına bakıldığında ise \% 20'sinin aktif çalıştığ 1 tespit edildi. Evre 5 takip süreleri ortancas1 16 ay (min:2-max:156), AVF'li takip süreleri ortancas1 11 ay (min:2 max:156) ve AVF açtırma kararı verildiğinde eGFH ortancası 10,9 $\mathrm{ml} / \mathrm{dk}$ (min:7-max:15,90) olduğu tespit edildi. AVF'lerin 4'ü (\%20) ikinci kez açılmıştı. İlk AVF'lerin çalışmama sebebi 2 hastada koruma hatas1, diğer 2 hastada ise trombüs kaynakl1 olduğu tespit edildi. AVF lokalizasyonuna bakı1dığında 13'ünün (\%65) radiyosefalik, 7'sinin (\%35) brakiyosefalik vende olduğu tespit edildi. Hastaların tümünde nabız, tril ve üfürüm var olup; 4'ünde (\%20) AVF açılan elde ve parmaklarda yapılan muayene sonucu hissizlik tespit edildi (Tablo 1). 15 (\%75) hastanın her gün fistülünü kontrol ettiği, 7 (\%35) hastanın her gün fistüllü koluyla ezgersiz yaptığ1, 17 (\%85) hastanın fistüllü kolunu dışardan gelecek darbelere karşı koruduğu saptandı. Fistüllü kolun üzerine yatmayan 14 (\%70) kişi, fistüllü koldan tansiyon ölçtürmeyen 19 (\%95) kişi, fistüllü kolla ağırlık kaldırmayan $18 \quad(\% 90)$ kişi olduğu saptandı. Hastaların tamamının fistüllü koldan kan aldırmadığı ve fistüllü kolunu sıkacak giysiler giymediği saptandı (Tablo 2).

Hastaların 15'inin (\%75) evde her gün düzenli tansiyon takibi yaptığ 1,15 'i (\%75) fistül sesinde bir azalma ya da değişiklik yaşamadığı, 16'sının (\%80) evde tansiyon düşmesi sorunu yaşamadığ 1 görüldü. Hastaların 17'si (\%85) evde tansiyonunun düştüğü durumlarda ve 17 hastanın da (\%85) yüksek ya da düşük sıcaklıklarda fistülünün çalışmasının etkilenebileceğini bilmediği tespit edildi (Tablo 3). 
Tablo 1. Arteriyovenöz Fistül Değerlendirmesine İlişkin Sonuçlar

\begin{tabular}{|l|c|c|c|c|}
\hline \multirow{2}{*}{ Bulgular } & \multicolumn{2}{|c|}{ Var } & \multicolumn{2}{c|}{ Yok } \\
\cline { 2 - 5 } & $\mathbf{n}$ & $\mathbf{\%}$ & $\mathbf{n}$ & $\mathbf{\%}$ \\
\hline Nabız & 20 & 100 & 0 & 0 \\
\hline Tril & 20 & 100 & 0 & 0 \\
\hline Üfürüm & 20 & 100 & 0 & 0 \\
\hline Ödem & 0 & 0 & 20 & 100 \\
\hline Kızarıllk & 0 & 0 & 20 & 100 \\
\hline Ağrı & 0 & 0 & 20 & 100 \\
\hline Hissizlik & 4 & 20 & 16 & 80 \\
\hline
\end{tabular}

Tablo 2. Hastaların fistüllü kolun korunmasıyla ilgili sorulara yanıtları

\begin{tabular}{|l|c|c|c|c|c|c|}
\hline \multirow{2}{*}{ Sorular } & \multicolumn{2}{|c|}{ Evet } & \multicolumn{2}{c|}{ Hayır } & \multicolumn{2}{c|}{ Bazen } \\
\cline { 2 - 7 } & $\mathbf{n}$ & $\mathbf{\%}$ & $\mathbf{n}$ & $\mathbf{\%}$ & $\mathbf{n}$ & $\%$ \\
\hline Her gün fistülünüzü kontrol ediyor musunuz? & 15 & 75 & 0 & 0 & 5 & 25 \\
\hline $\begin{array}{l}\text { Fistüllü kolunuzla her gün egzersiz yapıyor } \\
\text { musunuz? }\end{array}$ & 7 & 35 & 4 & 20 & 9 & 45 \\
\hline Fistüllü kolunuzun üzerine yatıyor musunuz? & 1 & 5 & 14 & 70 & 5 & 25 \\
\hline $\begin{array}{l}\text { Fistüllü kolu dışrdan gelebilecek darbelerden } \\
\text { koruyor musunuz? }\end{array}$ & 17 & 85 & 0 & 0 & 3 & 15 \\
\hline Fistüllü koldan tansiyon ölçtürür müsünüz? & 0 & 0 & 19 & 95 & 1 & 5 \\
\hline Fistüllü kolla ağırlık kaldırır mısınız? & 0 & 0 & 18 & 90 & 2 & 10 \\
\hline Fistüllü koldan kan aldırır mısınız? & 0 & 0 & 20 & 100 & 0 & 0 \\
\hline Fistüllı̈ kolunuzu sıkacak giysiler giyer misiniz? & 0 & 0 & 20 & 100 & 0 & 0 \\
\hline
\end{tabular}

Tablo 3. Hastalarin Fistülün Çalışmasını Etkileyebilecek Durumlarla İlgili Bilgi Durumları

\begin{tabular}{|l|c|c|c|c|}
\hline \multirow{2}{*}{ Sorular } & \multicolumn{2}{|c|}{ Evet } & \multicolumn{2}{c|}{ Hayır } \\
\cline { 2 - 5 } & n & \% & n & \% \\
\hline Evde hergün düzenli tansiyon takibi yapıyor musunuz? & 15 & 75 & 5 & 25 \\
\hline Fistül sesinde bir azalma ya da değişiklik oldu mu? & 5 & 25 & 15 & 75 \\
\hline Evde tansiyonunuz düşüyor mu? & 4 & 20 & 16 & 80 \\
\hline $\begin{array}{l}\text { Evde tansiyonunuzun düştüğü durumlarda fistülünn̈zzün } \\
\text { çalı̧masının etkilenebileceğini biliyor musunuz? }\end{array}$ & 3 & 15 & 17 & 85 \\
\hline $\begin{array}{l}\text { Yüksek ya da düşük sıcaklıklarda fistülünüzün } \\
\text { etkilenebileceğini biliyor musunuz? }\end{array}$ & 3 & 15 & 17 & 85 \\
\hline
\end{tabular}




\section{TARTIŞMA}

Çalışmamızda hastaların fistüllerini kontrol ve koruma konusunda yapması gereken davranışları yeterli bulundu. Isı değişimlerinin ve hipotansiyon durumunun fistülü etkilemesi ile ilgili bilgi düzeyleri ise yetersiz bulundu. Eksik olan konulardaki eğitimlerin tekrarı ve daha sonraki hastalar için bu konuların daha geniş ve vurgulanarak anlatılması gerektiği sonucuna varıldı.

Düşük klirens polikliniği eğitim hemşiresi; doğru beslenme, doğru ilaç kullanımı, kan basıncı ölçümü, aşılama gibi konuların yanında RRT hakkında da eğitim vermektedir. Hastanın kendi durumuna uyan en doğru RRT kararını vermesine destek olmaktadır. Hastaların düşük klirens eğitim hemşiresi tarafından eğitimlere alınması; RRT'ye geçiş sürecine kadar olan sürede yakın takip edilmesi, hastaların bu süreci komplikasyonsuz geçirmelerini ve RRT'ye daha bilinçli, fiziksel ve psikolojik olarak hazır şekilde geçmelerini sağlamaktadır (21).

Düşük klirens polikliniği eğitimleriyle hastalığın ilerlemesini önlemek, RRT hazırlıklarını tamamlayarak ve yakın takiple zamanından önce RRT'ye geçişi önlemek mümkündür. RRT'ye geçişte, e-GFH tek belirleyici faktör değildir. Semptomlar, günlük yaşam aktiviteleri, beslenme durumu ve diğer laboratuvar değerleriyle bütüncül yaklaşımla RRT'ye geçme kararının verilmesi gerekir (22-25).

Renal replasman tedavisi türünün seçimi her hastaya özel olmalı, medikal ve sosyal endikasyonlar gözden geçirilmeli, hasta ve yakınları RRT konusunda mutlaka son aşamaya gelmeden bilgilendirilmeli, seçim için zaman verilmeli, hastayı takip eden hekimin ve eğitim hemşiresinin önerileri dikkate alınmalıdır. Son kararı mutlaka hasta/hasta yakını vermelidir. Özellikle Evre 5 hasta eğitimlerinde; gelecekle ilgili korku ve endişelerin eğitimleri anlamaya engel olabileceği göz önüne alınarak daha dikkatli olunmalı ve mümkünse hasta yakınları da eğitimlere dahil edilmelidir. Hasta yakınlarının desteğinin sağlanması, hastaların RRT sürecinde de yalnız olmadığını hissetmesi açısından önemlidir.

Kronik HD hastalarında uzun süreli kaliteli yaşam, uygun ve yeterli damar yolu erişimiyle mümkündür. Hastalara gereğinden erken AVF oluşturulması kalp damar hastalıkları açısından sorunlara neden olabilir. Geç açılması da, hastanın ilk HD seansından itibaren AVF'nin kullanılamamasına sebep olabilir. Düşük klirens eğitim polikliniğinde 1.1.2016-30.6.2019 tarihleri arasında RRT'ye geçen 209 hastanın dahil edildiği çalışmada HD seçen 129 hastanın ilk diyalizine AVF ile girme oranının \%63,6 olduğu bildirilmiştir (26). Bu oranın arttırılması düşük klirens polikliniklerinin çoğalması ve aktif çalışmasıyla olabilir. $\mathrm{Bu}$ oran arttıça hastalara verilen AVF'nin önemi, bakımı ve koruma konularındaki eğitimin önemi daha da belirginleşecektir. AVF oluşturulmadan önce, olgunlaşma ve kullanım sürecinde hastalara yapılan AVF'ye yönelik düzenli eğitimler hastalarda gelişebilecek komplikasyonların önlenmesinde etkili olmaktadır (27).

AVF açtırma kararı verilirken; hasta bireysel değerlendirilmeli ve tahmini diyalize başlangıç tarihinden 4-6 ay öncesinden AVF oluşturulmalidır (6-10).

Düşük klirens polikliniğinde takibi yapılan HD tedavisini seçtikten sonra fistülü hazırlıkları yapılmış ve henüz HD tedavisine başlanmamış hastalarla ilgili literatürde herhangi bir çalışmaya rastlanmamıştır. Ayrıca benzer süreçlerden geçmiş HD tedavisi yapılan hastalarla ilgili çalışmalara da rastlanmamıştır. Aktaş'ın (2008) yaptığı çalışmanın sonuçları bizim çalışmamızdaki sonuçlar ile benzerdir. Hastaların \%92'si fistüllü koldan tansiyon alınmasında ve fistüllü koldan kan alınmasında sakınca olduğunu bildiğini, \%75,7'si fistüllü koluyla ağırlık kaldırmadığını \%79,6's1 fistüllü kolunu sıkacak k1yafet giymediğini ve yarıdan fazlası da fistüllü kolunu her gün kontrol ettiğini ifade etmiştir (28). Ovayolu'nun çalışmasında (2007) fistülün bulunduğu koldan hastaların \%89,4'ünün kan aldırmadığı, \%89,4'ünün tansiyon ölçtürmediği, \%84,8'inin ağır eşya kaldırmadığı, \%77,3'ünün sık1 kıyafetler giymediği, $\% 65,2$ 'sinin günlük fistül kontrolü yaptığ1 ve \%53'ünün hipotansiyon için önlem aldığı bildirilmiştir (29). Arslan ve Akça'nın (2018) yaptığı çalışma da ise hastaların $\% 88,2$ 'sinin fistül çalışmasını günlük kontrol ettiğin, \%78,4'ünün üç kilogramdan daha ağır bir 
şey taşımadığı, \%89,2'sinin fistül bölgesini sıkacak sıkı kıyafet giymediği, \% 89,2'sinin fistüllü koldan kan basıncı ölçümü yaptırmadığı ve \%49'unun fistül bulunan kolunu güçlendirmek için egzersiz yaptığ 1 bildirilmiştir (30).

\section{SONUÇ ve ÖNERILLER}

Düşük klirens polikliniklerinde hastaların AVF bakımı ve korunması için bazı bilgilerinin eksik olduğu saptanmıştır. AVF korunması için düşük klirens eğitimlerine uygun broşürler oluşturulması, hastaların karşılaştıkları veya karşılaşabilecekleri sorunları tespit edip bunları kapsayan fistül bakım takip formu ve eğitim kontrol formlarının oluşturulması gereklidir. Hastaların muayenede ilk karşılaştığı sağlı çalışanının eğitim hemşiresi olması nedeniyle bu sorunların tespiti konusunda eğitim hemşiresine büyük görev düşmektedir.

Hemodiyaliz tedavisinde karşılaşılabilecek sorunların önlenmesi açısından AVF'nin korunması hastanın damar yolu kullanım süresini uzatacaktır. RRT'de HD seçen hastalara AVF'nin önemi, korunması ile ilgili eğitimler verilmelidir. Henüz HD tedavisine başlamayan hasta grubu oldukları için eğitimler sı sı gözden geçirilmeli, gerektiğinde hastaya eğitim tekrarı yapılmalı ve basılı eğitim broşürleri ile bu eğitimler pekiştirilmelidir. Düşük klirens polikliniğinde AVF açılmasının son aylara bırakılmaması hastanın HD'ye girmeden birkaç ay önce AVF ile birlikte yaşamayı öğrenmesine ve fistülün olgunlaşmasına zaman tanımaktadır. Ayrıca diyaliz öncesi yapılan bu hazırlık süreci hastaların fistülle yaşamaya ilişkin farkındalık oluşturmasına da katkı sağlamaktadır. Böylece fistül açıklığının uzun süre devam ettirilmesine ve istenmeyen komplikasyonların önlenmesine yardımcı olmaktadır. AVF açıldıktan sonra hasta eğitimlerine öncelik verilmelidir. AVF'si olgunlaşmış şekilde takip edilen hastaları her ay rutin muayeneleri yapılmal1, muayene sirasinda AVF'leri kontrol edilmeli, AVF bakımı ve korunması için eğitim tekrarları yapılmalıdır. AVF'lerin takibinde nefrolog, cerrah, eğitim ve hemodiyaliz hemşiresinden oluşan multidisipliner bir ekibin bulunması önerilir. Cerrah fistülü açtıktan sonra sorun olmadığını belirttiğinde, açılan fistülün HD'de kullanılabilir olduğunun kararı için hemodiyaliz hemşiresinin yorumunun da alınması gereklidir. Tril veya üfürüm alınabilen fistülün giriş için uygunluk kararını bu konuda tecrübeli hemodiyaliz hemşiresinin vermesi daha uygun olacaktır.

Düşük klirens polikliniklerinde AVF ile izlenen hastalar için standart bakım ilkeleri geliştirilmelidir. Literatürde düşük klirens polikliniklerinde AVF'si hazır bekleyen hastaların takibiyle ilgili yeterli çalışma bulunmaması nedeniyle konu ile ilgili geniş kapsamlı çalışmalar yapılması önerilmektedir.

\section{Teşekkür/ Acknowledgements}

\section{Finansal destek}

Yazarlar herhangi bir finansal destek alınmad1ğını beyan etmişlerdir.

\section{Çıkar çatışması}

Yazarlar herhangi bir çıkar çatışması olmadığını beyan etmişlerdir.

\section{Hakemlik}

Çift kör hakemlik süreçleri uygulanmıştır.

\section{Yazarlık Katkıları}

Çalışma fikri ve tasarımı: EA, FB

Veri toplama ve analizi: EA, FB

Makalenin hazırlanması: EA, FB

Eleştirel inceleme: EA, FB 


\section{Kaynaklar}

1. Süleymanlar G. Chronic Kidney Disease and Failure: Definition, Stages and Epidemiology. Turkiye Klinikleri J Int Med Sci 2007;3(38):1-7.

2. Sijpkens YW, Berkhout-Byrne NC, Rabelink TJ. Optimal predialysis care. NDT Plus 2008;1(suppl_4):iv7-iv13. doi: 10.1093/ndtplus/sfn117

3. Jemcov, T. K., \& Van Biesen, W. (2017). Optimal timing for vascular access creation. The Journal of Vascular Access 2017;18.1_suppl: S29-S33. doi: 10.5301/jva.5000685

4. Jindal K, Chan CT, Deziel C, Hirsch D, Soroka SD, Tonelli M, Culleton BF. Hemodialysis clinical practice guidelines for the Canadian Society of Nephrology. Journal of the American Society of Nephrology: JASN 2006;17.3 Suppl 1: S127. doi: 10.1681/asn.2005121372

5. Besarab A. Clinical practice guideline for vascular access. Am J Kidney Dis, 2006, 48: s176-s247.

6. Nesrallah GE, Mustafa RA, Clark WF, Bass A, Barnieh L, Hemmelgarn BR., et al. Canadian Society of Nephrology 2014 clinical practice guideline for timing the initiation of chronic dialysis. CMAJ 2014;186(2):112-7.

7. Dember LM, Beck GJ, Allon M, Delmez JA, Dixon BS, et al. Effect of clopidogrel on early failure of arteriovenous fistulas for hemodialysis: a randomized controlled trial. Jama 2008;299(18): 2164-71.

8. Beathard GA. An algorithm for the physical examination of early fistula failure. Seminars in dialysis. Oxford, UK: Blackwell Science Inc 2005;18(4):331-5. doi: 10.1111/j.1525-139X.2005.18314.x

9. Robbin ML, Chamberlain NE, Lockhart ME, Gallichio MH, Young CJ, et al. Hemodialysis arteriovenous fistula maturity: US evaluation. Radiology 2002;225(1):59-64.

10. Third NKF-K. "Clinical practice guidelines for vascular access: update 2000." Am. J. Kidney. Dis. 2001;37(1): S137S181.

11. Lee HS, Song YR, Kim JK, Joo N, Kim C, et al. Outcomes of vascular access in hemodialysis patients: Analysis based on the Korean National Health Insurance Database from 2008 to 2016. Kidney Research and Clinical Practice 2019;38(3): 391.

12. Arhuidese IJ, Orandi BJ, Nejim B, Malas M. Utilization, patency, and complications associated with vascular access for hemodialysis in the United States." Journal of Vascular Surgery 2018;68(4): 1166-74.

13. Quinn RR, Oliver MJ, Devoe D, Poinen K, Kabani R, et al. The effect of predialysis fistula attempt on risk of all-cause and access-related death. Journal of the American Society of Nephrology 2017;28(2): 613-20.

14. Feddersen MA, Simon DR. Arteriovenous fistula surveillance: everyone s responsibility. Portuguese Journal of Nephrology \& Hypertension 2012;26(4): 255-65.

15. Süleymanlar G. Kronik Böbrek Hastalığı ve Yetmezliği. Arık N, Ateş K, Süleymanlar G, Tonbul HZ, Türk S, ve ark. eds. Hekimler İçin Hemodiyaliz Kaynak Kitabı. 1. Baskı. Ankara: Güneş Tıp Kitabevi; 2009

16. Prevention A, Tokars M, \& Andrus M. Electronic reporting of infections associated with hemodialysis." Nephrology news \& issues June 2005:37-43. Retrieved from: http://citeseerx.ist.psu.edu/viewdoc/download?doi=10.1.1.467. $3904 \&$ rep $=$ rep $1 \&$ type $=$ pdf

17. Astor BC, Eustace JA, Powe NR, Klag MJ, Fink NE, et al. Type of vascular access and survival among incident hemodialysis patients: the Choices for Healthy Outcomes in Caring for ESRD (CHOICE) Study. Journal of the American Society of Nephrology 2005;16(5): 1449-55.

18. Brunori G, Ravani P, Mandolfo S, Imbasciati E, Malberti F, et al. Fistula maturation: doesn't time matter at all?. Nephrology Dialysis Transplantation 2005;20(4):684-87.

19. Dhingra RK, Young EW, Hulbert-Shearon TE, Leavey SF, Port FK, et al. Type of vascular access and mortality in US hemodialysis patients. Kidney international 2001;60 (4):1443-51.

20. Klang B, Björvell H, Clyne N. Predialysis education helps patients choose dialysis modality and increases disease-specific knowledge. Journal of Advanced Nursing 1999;29(4): 869-76.

21. Asar E, Bora F, Erol A, Şanlı T, Bozkurt N, Çetinkaya R, Sarı F, Ersoy F, Süleymanlar G. Nefroloji Düşük Klirens Polikliniğinde Hasta Eğitim Süreci: Olgu Sunumu . Nefroloji Hemşireliği Dergisi 2019;14(1):33-43.

22. Tattersall J, Dekker F, Heimbürger O, Jager KJ, Lameire N, et al. When to Start Dialysis: Updated Guidance Following Publication of the Initiating Dialysis Early and Late (Ideal) Study. Nephrol Dial Transpl 2011;26(7): 2082-86.

23. Piccoli G. The Canadian Society of Nephrology 2014 clinical practice guideline for timing the initiation of chronic dialysis: a paradigm shift and the return of the clinical nephrologist. Giornale italiano di nefrologia: organo ufficiale della Societa italiana di nefrologia 2014;31.3.

24. Stevens PE, Levin A. Kidney Disease: Improving Global Outcomes Chronic Kidney Disease Guideline Development Work Group Members. Evaluation and Management of Chronic Kidney Disease: Synopsis of the Kidney Disease: Improving Global Outcomes 2012 Clinical Practice Guideline. Ann Intern Med. 2013; 158(11): 825-30. 
25. Watanabe Y, Yamagata K, Nishi S, Hirakata H, Hanafusa N, et al. Japanese Society For Dialysis Therapy Clinical Guideline For "Hemodialysis İnitiation For Maintenance Hemodialysis"; Ther Apher Dial 2015;19: 93-107.

26. Asar E, Bora F, Şanlı T, Bozkurt N, Çetinkaya R, Sarı F, Ersoy F.F, Süleymanlar G. Düşük Klirens Polikliniğinde Renal Replasman Tedavilerine Geçiş Süreci; Akdeniz Üniversitesi Örneği 29. Ulusal Nefroloji Hemşireliği Kongresi Bildiri Özet Kitab1, 2019, Antalya.

27. Pessoa NRC, Linhares FMP. Hemodialysis patients with arteriovenous fistula: knowledge, attitude and practice. Escola Anna Nery, 2015;19(1):73-79.

28. Aktaş B. Hemodiyaliz Tedavisi Gören Hastaların Fistül Bakımı ve Korunması ile ilgili Bilgi Düzeylerinin Değerlendirilmesi, Yüksek Lisans Tezi, Haliç Üniversitesi Sağlık Bilimleri Enstitüsü, İstanbul, 2008

29. Ovayolu N. Hemodiyaliz hastalarının fistül bakımına ilişkin uygulamaları. Türk Nefroloji Diyaliz ve Transplantasyon Dergisi 2007;16 (4):151

30. Arslan DE, Akca NK. Pain following needle insertion into a hemodialysis fistula and influencing factors. International Journal of Caring Sciences 2018;11(3):1662-1670. 